Arylamidase-Gehalt deutlich ansteigt, darf angenommen werden, daß zumindest ein beträchtlicher Teil dieser Zellen den proximalen Tubuli entstammt. Bei Annahme der physiologischen Mauserung der Tubulusepithelien als Hauptquelle der normalen Arylamidase-Ausscheidung im Urin (4) sollte bei Steigerung der Zellabschilferung um ein mehr als Hundertfaches eine entsprechende $\mathrm{Zu}-$ nahme der Aktivität des Überstandes eintreten: Eine solche konnte jedoch nicht festgestellt werden: die Werte blieben innerhalb der Normgrenzen (Abb. 4). Demnach scheint die Urin-Arylamidase zumindest für eine durch Aspirin erheblich gesteigerte Abschilferung von Tubulusepithelien nicht das erhoffte empfindliche $\mathrm{Maß}$ darzustellen.

\title{
Literatur
}

1. Nagel, E., F. Willig und F. H. Schmidt, Klin. Wschr. 42,447 (1964). - 2. Patterson, E. K., A. Keppel und Shu-Hsi Hsiao, J. Histochem. Cytochem. (Baltimore) 9, 608 (1961). - 3. Patrerson, E. K., Shu-Hsi-Hsiao und A. Keppel, J. biol. Chemistry 238, 3611 (1963). - 4. Klaus, D., Aerztl. Forschg., Wörishofen 15, 548 (1961); 16, 9 und 18 (1962). - 5. Bergmann, H., Arch. klin. exp. Derm. 219, 500 (1964). - 6. BergmanN, H., Habilitationsschr. Göttingen (1965). - 7. BergmanN, H. und G. F. KlostermanN, Arch. klin. exp. Derm. 218, 603 (1964). - 8. Bergmann, H. und F. Scheler, Klin. Wschr. 42, 275 (1964). -9. BergmanN, H. und F. Truss, Med. Welt. 34, 1760 (1964). - 10. BergmanN, H., S. Estrich, F. Scheler und M. Schmidt, Aerztl. Labort. 9, 255
(1963). - 11. Tuppy, H., U. Wiesbauer und E. Wintersberger, Hoppe-Seyler's Z. physiol. Chem. 329, 279 (1962). - 12. RAAB, W., diese Z. 4, 56 (1966). - 13. Dubach, U. C., Helvet. med. acta 33, 139 (1966). - 14. Prescott, L. F., Lancet $I I, 91$ (1965). - 15. Goldbarg, J. A. und A. M. Rutenburg, Cancer, N. Y. 11, 283 (1958). - 16. Golisch, G., Klin. Wschr. 38, 968 (1960). - 17. Rutenberg, A. M., J. A. Goldbarg und E. P. Pineda, N. England J. Med. 259, 469 (1958). - 18. Szasz, G., P. Baranyar, Z. Czirbesz und P. Csakt, Klin. Wschr. 43, 783 (1965). - 19. Jösch, W. und U. C. Dubach (in Vorbereitung). - 20. NaChlas, M. M., B. Monis, D. Rosenblatt und A. M. Seligman, J. biophysic. biochem. Cytol. 7, 261 (1960).

Priv.-Doz. Dr. U. C. Dubach

CH 4056 Basel, Hebelstr. 1

\section{Die Bilirubinbestimmung nach Ferro und Ham im Serum}

\author{
Von E. Gladtke \\ Aus der Kinderklinik der Universität Gießen (Direktor: Prof. Dr. F. H. Dost)
}

(Eingegangen am 25. März 1966)

Die Bestimmung des Bilirubins nach Ferro und HAM, die auf einer Oxydation des Bilirubins im sauren Milieu zu einem blauen Farbstoff mit Hilfe von Ferrichlorid beruht, kann wegen unterschiedlicher Adsorption des Farbstoffes an den Eiweißniederschlag sowohl bei verschiedenen Serumeiweißkonzentrationen als auch bei verschiedenen Bilirubinkonzentrationen nicht empfohlen werden.

The determination of bilirubin according to FERRo and HAM, which depends upon an oxidation of bilirubin with ferric chloride in acid medium to give a blue colour, cannot be recommended: there is an adsorption of the coloured material onto the protein precipitate, which varies both with the concentration of serum protein and with the concentration of bilirubin.

In der Pädiatrie besteht vor allem seit Kenntnis der kausalen Zusammenhänge zwischen Bilirubinkonzentration und Kernikterus und der Möglichkeit der Verhütung des Letzteren ein großes Interesse an der Bestimmung des Bilirubins im Serum. Insbesondere jede Möglichkeit zur Vereinfachung der Analyse ist von Nutzen. Wir haben deshalb die von Ferro und HAM (1) empfohlene Methode zur Bestimmung des sog. gesamten Bilirubins kritisch untersucht, da sie den Vorteil hat, mit einem stabilen Misch-Reagenz, also mit zwei Pipettierungen (Serum bzw. Standard- oder Leerwert und Reagenz) pro Ansatz auszukommen.

\section{Methodik}

Die Methode beruht darauf, daß Bilirubin bei saurer Reaktion in einen blauen Farbstoff übergeht, dessen Konzentration photometrisch bestimmt wird. Die Umsetzung wird durch Ferrichlorid (offenbar katalytisch) beșchleunigt.
Ferro und Ham säuern mit Trichloressigsäure an, verwenden Isopropanol zur Extraktion der Farbe aus dem Eiweißniederschlag und bringen mit Äthylenglycolmonomethyläther die Lipide in Lösung. Diese drei Reagenzien werden zusammen mit Ferrichlorid zu einem Reagenz angesetzt ( $90 \mathrm{~g}$ Trichloressigsäure, Isopropanol auf $900 \mathrm{~m} l, \quad 100 \mathrm{~m} l$ Äthylenglycol-monomethyläther und $1 \mathrm{~m} /$ einer 7,2-proz. wäßr. Lösung von $\mathrm{FeCl}_{3} \cdot 6 \mathrm{H}_{2} \mathrm{O}$ ), das im Verhältnis $10 \mathrm{zu} 1$ (10 Teile Reagenz, 1 Teil Serum) mit Serum vermischt, nach 5 Min. filtriert und nach $30 \mathrm{Min}$. bei $660 \mathrm{~m} \mu$ gemessen wird.

$\mathrm{Da}$ uns nur eine relativ geringe Menge Originalreagenz zur Verfügung stand, wir außerdem nur kleine Serummengen einzusetzen beabsichtigten, adaptierten wir die Methode zunächst an den Mikrolitermaßstab, in dem wir $20 \mu l$ Serum mit $200 \mu l$ Reagenz versetzten; wir blieben damit beim vorgeschriebenen Mengenverhältnis. Die Filtration wurde durch Zentrifugation ersetzt. Ferro und HaM empfehlen in einer zweiten Publikation (2) ein ähnliches Vorgehen mit allerdings etwas größeren Men- 
gen $(50$ und $500 \mu \mathrm{l})$. Im Mikrolitermaßstab erhielten wir beim Messen in $1 \mathrm{~cm}$ Schichtdicke in Mikroküvetten die gleichen Extinktionen wie beim Ansatz mit den Mengen der Originalvorschrift ( $1 \mathrm{~m} l$ Serum, $10 \mathrm{~m} l$ Reagenz).

Zur kolorimetrischen Messung ist nur ein Photometer mit Glühfadenlampe oder mit Cadmiumlampe geeignet, da im Bereich zwischen 640 und $700 \mathrm{~m} \mu$, in dem die blaue Farbe ihr Adsorptionsmaximum hat, keine genügend starke Quecksilber-Linie existiert. Wir bedienten uns eines Eppendorf-Photometers mit Multiplier und verwendeten die Cadmium-Linie $644 \mathrm{~m} \mu$.

\section{Versuchsanordnung}

$\mathrm{Da}$ bei dieser Methode mit Eiweißfällung und Extraktion gearbeitet wird, war die entscheidende Frage, ob die Extraktion vollständig oder wenigstens proportional zum Bilirubingehalt und unabhängig von der Menge des Niederschlags und damit unabhängig vom Eiweißgehalt erfolgen würde.

Nachdem Eichkurven aus wäßriger und albuminhaltiger Bilirubinlösung identisch und linear verliefen, wurde das Verhalten im Serum untersucht.

$\mathrm{Zu}$ diesem $\mathrm{Zweck}$ wurde eine $80 \mathrm{mg}$-proz. Bilirubinlösung in $0,1 \mathrm{M}$ Natriumcarbonatlösung $(80 \mathrm{mg}$ in $100 \mathrm{~m} /$ ) nach SCheliong und Wende (3) hergestellt, daraus durch Verdünnen mit Bilirubin-armem Plasma entsprechend niedere Konzentrationen gemischt, und die Bestimmungen durchgeführt. Der Bilirubingehalt der jeweiligen Plasmacharge wurde gesondert bestimmt und abgezogen. Es wurden Ansätze mit etwa $6 \mathrm{~g}$ und mit etwa $3 \mathrm{~g}$ Eiweiß pro $100 \mathrm{ml}$ verglichen.

\section{Ergebnisse und Diskussion}

Die in der Tabelle und in der Abbildung aufgeführten Ergebnisse zeigen, daß mit zunehmendem Eiweißgehalt die Extinktion und damit die gemessene Konzentration bei gleicher eingesetzter Bilirubinmenge geringer wird. Gleichzeitige Bestimmung aus dem gleichen Ansatz nach Jendrassik und Cleghorn (nach With (4)) ergab dagegen bei verschiedenem Eiweißgehalt und gleicher vorgelegter Bilirubinmenge die gleiche Extinktion.

Außerdem ergibt sich aus den Werten der Abbildung 1, $\mathrm{da} ß$ mit zunehmender Bilirubinkonzentration bei gleicher Eiweißkonzentration die Extinktion nicht linear zunimmt. In wäßriger Lösung dagegen nimmt die Extinktion linear zu, ebenso in albuminhaltiger Lösung. Die Kurve folgt damit im Serum bzw. in Eiweißlösung nicht dem Lambert-Beer'schen Gesetz, sondern ist nach unten abgebogen. Das heißt aber, daß bei zunehmender Bilirubinkonzentration eine zunehmend relativ größere
Tab. 1

Extinktionen bei $644 \mathrm{~m} \mu(10 \mathrm{~mm})$ von $8 \mathrm{mg} \%$ Bilirubin bei Ansätzen mit verschiedenen Chargen des Reagenz nach FERRO und HAM

\begin{tabular}{ccc}
\hline $\begin{array}{c}\text { Versuch- } \\
\text { Nr. }\end{array}$ & $3(2,7-3,1) \mathrm{g} \%$ & $6(5,4-6,2) \mathrm{g} \%$ \\
\hline 1 & 0,392 & 0,309 \\
2 & 0,265 & 0,216 \\
3 & 0,296 & 0,260 \\
4 & 0,348 & 0,331 \\
\hline
\end{tabular}

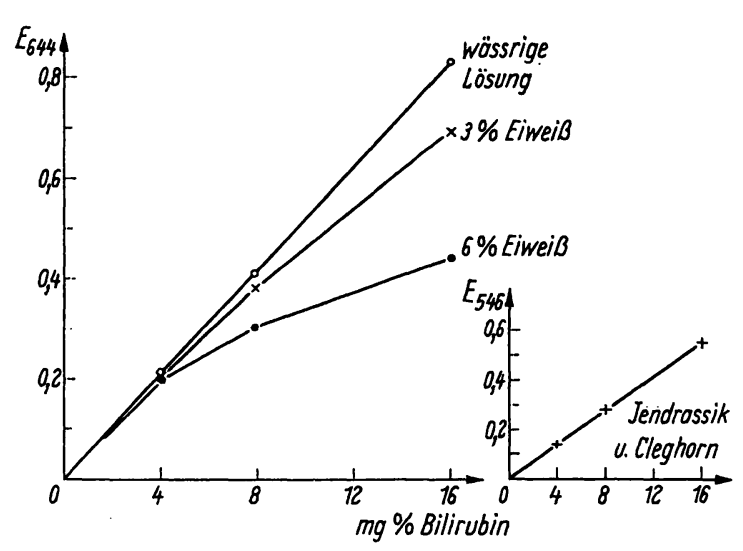

Abb. 1

Das Verhalten der Extinktion bei steigender Bilirubin-Konzentration in Lösungen verschiedenen Eiweißgehaltes

Links: Methode nach FERRO und HAM; rechts: nach JENDRASSIK und ClegHORN

Menge Bilirubin nicht als Farbkomplex in der gemessenen Phase erscheint. Offenbar wird, wie es auch die blaugrüne Färbung des Niederschlags ausweist, eine jedenfalls nicht der Konzentration proportionale Menge des Farbstoffs an den Eiweißniederschlag adsorbiert und somit der Messung entzogen. Gleichzeitige Bestimmung aus dem gleichen Ansatz nach JeNDrassik und ClegGHORN ergab dagegen einen linearen, der jeweiligen Bilirubinkonzentration entsprechenden Anstieg der Extinktion. Die Methode nach FerRo und HaM besticht durch ihre Einfachheit und durch die Stabilität der Farbe, wenn auch die Inkubationsdauer von 20 Min. gegenüber der Diazomethode keinen Zeitgewinn einbringt. Aber wie bei allen Methoden zur Bilirubinbestimmung, die mit Eiweißfällung arbeiten, ist die Adsorption des Farbstoffes an den Niederschlag ein entscheidender Nachteil, der die Methode mit einem zu großen Fehler belastet. Gerade beim Neugeborenen kann die Serumeiweißkonzentration innerhalb eines relativ großen Bereiches schwanken, so daß hier die Fehler nicht mehr kontrollierbar werden.

Leider kann somit nach den vorliegenden Ergebnissen die Methode der Bestimmung des gesamten Bilirubins nach FERRo und HAM nicht empfohlen werden.

\section{Literatur}

1. Ferro, P. V. und A. B. Ham, Amer. J. Clin. Path. 40, 209 (1963). - 2. Ferro, P. V. und A. B. HaM, Amer. J. Clin. Path. 44, 111 (1965). - 3. Schellong, G. und U. Wende, Klin. Wschr. 38,
703 (1960). - 4. Wrrm, T. K., Hoppe-Seyler's Z. physiol. Chem. 278, 133 (1943).
Priv.-Doz. Dr. med. E. Gladtke, 63 Gießen, Gutenbergstr. 24 